\title{
Language Reconfigurations: From Literate Culture to Visual and Audiovisual Culture
}

\author{
Zulma P. Sánchez Beltrán \\ Universidad Pedagógica Nacional, Bogotá, Colombia.
}

How to cite this paper: Zulma P. Sánchez Beltrán. (2020) Language Reconfigurations: From Literate Culture to Visual and Audiovisual Culture. Journal of Humanities, Arts and Social Science, 4(1), 79-88. DOI: $10.26855 /$ jhass.2020.01.010

Received: April 29, 2020

Accepted: May 30, 2020

Published: July 10, 2020

*Corresponding author: Zulma P. Sánchez Beltrán, Universidad Pedagógica Nacional, Bogotá, Colombia.

Email: zpsanchezb@pedagogica.edu.co

\begin{abstract}
This article explores some considerations on the reconfiguration of language, moving from the alphanumeric culture of the literacy to the visual and audiovisual culture, partially based of the results derived from the doctoral research: Visual Artistic Education in Digital Contexts. The main objective of the research was to understand the relationship between visual arts education (VAPE) and digital culture in function of the learning, through the uses and appropriations made by the youngest in the eleventh grade of the YouTube platform. To achieve this objective, the methodology used was qualitative, through micro-ethnographic work based on participative observation along with the young people. Based on the uses and appropriations that young people make of the YouTube platform in terms of learning by the VPAE, various relationships were identified between visual-plastic artistic education and digital culture, the first of these relationships revolves around Language, since both visual plastic art education and contemporary technological repertoires appeal to the use of language other than alphanumeric and literacy culture, especially those such as visual and audiovisual language, including narrative, body, poetic language, among others. This shows the importance and relevance of other manifestations of language in culture and the ways in which communication is configured between those who make it, where there seems to be a change from the forms of alphanumeric and literate culture to visual and audiovisual forms of language.
\end{abstract}

\section{Keywords}

Visual-Plastic Artistic Education, YouTube, Young People, Language

\section{Introduction}

During the last decade, it has been common to hear that communication and information technologies (CIT) have changed social practices in general, noticing, according to Tirocchi (2019), "indissoluble links between online platforms and social structures" (p. 204). It is also a fact that most of people's daily activities are constituted by a few, but substantial, platforms where time and attention are spent as part of daily life. According to the author,

contributing to transforming social practices, amen as influencing the democratic and civil reality: Amazon, Google or Facebook, to name a few examples, are social devices that, in addition to structuring reality, lead and define universes of values. Their influence is visible in many areas, including education (2019, p. 204).

In the case of the school, these practices have affected in a transcendental way the knowledge, the work and the school itself respect to the knowledge of the young people. Therefore, the school has been mobilized to relate and 
adapt more and more to the practices of the youngest, as leaders and protagonists of the teaching and learning processes and, in an important way in the current historical moment, related with the installation of CIT or the contemporary technological repertoires (from now on CTR).

The nomination of CTR is retaken from researchers such as Rocío Rueda (2013), among others, for whom CTRs more than been instruments involves environments of creation, socialization, and learning, from which it is possible to develop, empower, and integrate intellectual competencies. The term repertoires is related to the use of languages and notational systems that allow the transformation of different socio-cultural dimensions, including the educational one.

\section{Context}

Likewise, the CTRs have affected visual-plastic arts in terms of production, circulation, access, consumption, uses and appropriations of the knowledge they entail in themselves. As far as visual-plastic arts education is concerned, they play a determining role in the understanding and transformation of the so called visual speeches on the Web, including those of the visual-plastic arts in an expanded dimension.

Authors like Freedman (2006) claim that a daily contact with technological images, computer games and searches on the Internet are part of young people's daily lives, especially outside school. In the same way, the generalized images are for some the democratization of the image, "that regarding the world linguistic differences, the Fine Arts, the feature films, the comics (like manga) and many other forms of visual culture have crossed the textual limits" (Freedman, 2006, p. 12).

On the other hand, Eisner (1995) points out that "art appears as another system of signification, through visual and audiovisual forms" (p. 31), and that "cinema, video, the numerous exhibitions made possible by the computer and even poetically elaborated narration will have their turn behind the scenes. I think we won't have to wait that long until they are called to the center of the scene” (p. 184). In that sense, authors like Dussel and Corbeta (2018), maintain that artistic education is one of the areas from which visualities are produced and generated, "they propose visual repertoires and ways of reading and working with the image that have organized hierarchies and relations with the visuality" (p. 17).

The CTRs have played a relevant role on the configuration of other ways of communicating, of building sensibilities and learning with the young people of the last century. This is about transformations in the forms of the structure of language, since both the media and the CTRs, little by little, have been constituted as new training scenarios, in the case of education. It would seem, then, that the school no longer fulfills the role of training exclusively at the social level, since for more than half a century it has been shared with other institutions, as Alvarez (2003) refers to the educational society and Martin-Barbero with the educational society (2002).

Today other processes of reproduction of manners, behaviors and logics of understanding take place, which according to Chapato and Dimatteo (2014):

"the school cannot ignore the relations between the social phenomenon that generate new conditions for the functioning of institutions, the new conditions of production, circulation and cultural appropriation, and the educational possibilities of individuals to participate on them” (p. 36).

These new conditions for the institutional functioning of schools are not only evident in the relations of the educational actors, but also in the construction of knowledge and the forms of expression that these networks of meaning take. Languages such as visual, audio-visual, and narrative appear predominantly, as well as poetic and corporal languages, among others, from the emergence of a digital culture and new technological supports that complement the written culture.

The school faces new forms of interaction between the different actors that compose it, where cultural transformation is constituted by the repertoires that mediate in the modes of communication and organization of social bonding, which in turn, as mentioned, have effects on the forms of production and circulation of knowledge. Consequently, it is a matter that directly involves the way in which the chain of meanings that constitutes language is constructed, as well as at the level of aesthetics and the agency of young people, but whose emphasis, for the present article, is sustained in the production and manifestation of language in the relations of young people with the school and the CTRs in terms of learning the VPAEs. This exposes a challenge for the school at an structural level, not only institutional in the reproduction of knowledge, but also in its social and cultural practice.

To that extent, it is found that language appears as one of the key points of the disturbances in which the school is anchored, for which traditionally knowledge has been assimilated with the capacity to express itself exclusively 
in a verbal and written way, assuming and considering it as "a superior medium from the visual and tactile modes" (Dondis, 1976, p. 21). It may be thought that other possibilities of knowing and learning have been unknown, as well as different visu-spatial strategies that are adapted to the learning style. According to Barbero and Rey (1999), the school "embodies and prolongs, like no other institution, the regime of knowledge that instituted the communication of the printed text", as a communicational and educational paradigm that establishes a double correspondence: "between the linearity of the written text and school development-intellectual progress goes parallel to the reading progress" (p. 41).

Mirzoeff (2006), points out that the literate culture has been given privilege as the highest form of intellectual practice, on account of the alliances between school, printing and written text, to the detriment of the visual representations. Dondis (1976), states that, in the field of the visual, the educational system "progresses with monolithic slowness", persisting the relevance and emphasis in the verbal and written mode, excluding "the rest of the human sensibilities", as well as the "overwhelmingly visual character of the child's learning experience" (p. 22).

Despite the fact that the quoted authors' statements date from the 1970s (Dondis), the 1990s (Rey \& Barbero), until 2006 (Mirzoeff), thirteen years later, it seems that the panorama is not that different, especially for the field of education and pedagogy in the context of the current CTR, which proposes the urgency of learning, appropriation and practice of other ways of manifestation of the language, beyond the alphanumeric and literate ones.

In this sense, authors such as Caldeiro-Pedreira, Aguaded, \& Peréz-Rodríguez (2019), Renés-Arellano, Pérez-Lisboa, Hinojosa-Becerra (2019), Pérez-Rodríguez, Delgado-Ponce, García-Ruiz, and Caldeiro-Pedreira (2015), agree on the necessity of a media literacy based on the communicative and audiovisual capacity and competence, focused on the development of the language dimension, allowing, not only the adequate reception of audiovisual contents, but especially their decoding and their analysis in a reflexive and autonomous way.

It is recognized then as a pending issue at the curricular level the conceptual theoretical expansion about the modes of literacy and language that involve the audiovisual dimension in relation to the CTR, besides its traditional relation, as already mentioned, with reading and writing. Therefore, in the current panorama and rise of the CTR, it is necessary to include other manifestations of language, beyond the alphanumeric and literate culture, that allows the decoding and comprehension of symbolic systems and forms. Through the contemporary technological repertoires, not only is information produced, diffused, and circulated, but other languages are also linked through different mechanisms of access, storage, diffusion, and production, which generate relations and communicative interactions through languages and mechanisms that are very different from those that are the object of teaching and learning in schools.

The previous is directly related to the VPAE, understood as the teaching-learning processes of the set of practices and artistic visual-plastic knowledge as symbolic, aesthetic and ideological content of particular contexts and times, expressed in visual images. These images can be two-dimensional, three-dimensional, audiovisual, multimedia and/or multimodal, through the creation, appropriation and transformation of techniques and critical and propositional experimentation of the media.

Under this perspective, the general objective of the research developed was to understand the relations between visual-plastic arts education and digital culture in function of learning, through the uses and appropriations made by the eleventh grade youth of the José María Córdoba School on the YouTube platform. In this sense, it is found that both the V.P.A.E. and the CTR appeal to the use of languages different than the alphanumeric and literate culture, especially those such as visual and audiovisual language, being these languages the main point of reflection of this article.

The research showed that young people feel more attracted, motivated and find greater understanding and affinity with information that is worked in a visual, audiovisual and narrative way, giving privilege today to images as a place and medium for communication and learning and, therefore, more visual and audiovisual forms and ways of language.

In this way, images and their narratives for both the CTRs and the VPSE are assumed as forms of expression, communication and cultural knowledge of themselves and others, involving the meaning and sense of their own experience through materials, forms and particular languages of their time-space. They allow the recognition of the world, thinking and thinking of oneself from other places, other ways of reflection and proposal, of representation and presentation with the capacity to understand and become aware of the meanings that are shared as a group through cultural devices, in this case, the technological repertoires determined especially by visual and audiovisual languages. 


\section{Methodology}

The methodology used was qualitative, based on the development of field work in two different but complementary scenarios. Two methodological phases were performed during one semester: the first, a micro-ethnographic work in the Laboratory Ático of the Pontificia Universidad Javeriana (P.U.J), to observe the uses and appropriations that young people make of the YouTube platform, in terms of learning the Visual-plastic Arts.

The second phase, called "pedagogical research through visual-plastic arts" (PRVPA), conducted within the José María Córdoba (JMC) school institution, corresponds to the processes of recognition and comprehension of the experiences of young people, the levels of appropriation of the information gathered and managed in the laboratory, as well as the learning experiences obtained or made by young people through their visual and audiovisual narratives.

As mentioned, for the purposes of the article and given the amplitude of the investigation and its results, the emphasis is on language and its reconfigurations in light of the uses and appropriations that young people generated on the YouTube platform in terms of learning - in the case of VPA (however, it may be applicable to learn other disciplines or school and/or academic subjects).

Thus, the micro ethnographic work based on participative observation with young people in the Laboratory Ático of the Pontificia Universidad Javeriana (P.U.J), besides providing a scope to the main objective of the research, seeks to answer one of the articulating questions of the research: How do young people use and appropriate platforms such as YouTube for learning purposes of particular knowledge?

During the participative observation, in addition to the researcher's field diaries (FD), data were collected through other instruments such as blogs (BJ) or writings by the young people about what happened during the session, in which they narrated how they conducted the searches. Interviews (IN) and semi-structured counter-interviews (SCI) were conducted, oriented to evidence the uses, achievements and limitations of the searches in terms of teaching-learning. Finally, a virtual route (VR.) was carried out through e-mail, so that the young people could send individually and in a more detailed way the links of the videos that they found, as well as comments of each one and the reasons of their choices. Given the range and variety of the videos-due to the time limitations-it was not possible to visualize and socialize each and every one of the videos, but we tried to recognize the process and perceptions of each younger and their findings. This virtual route was only a moment in the micro-ethnographic process, which is why a virtual ethnography was not necessary. $90 \%$ of the observation and follow-up was done in person in the Ático laboratory and in the classroom facilities.

The information collected by each of the instruments was tabulated, transcribed and systematized, including: 20 teachers' field diaries (DC), 90 youth logbooks (BJ) - in which their perceptions of each session in Ático were collected; 75 virtual route emails (VR), 21 interviews (IN) and 21 semi-structured individual interviews (SSI). The cross-interview involves a second interview after several sessions in the Ático laboratory and the first interview, seeking to determine, verify, expand and/or complement the information, which allowed to refine statements and perceptions of young people about the uses and appropriations of the platform.

In the micro-ethnographic phase, 227 information records were consolidated, which only $10 \%$ corresponded to teachers and $90 \%$ to young people. All the information collected in this phase and its respective instruments was tabulated, systematized and analyzed, from content analysis with a descriptive and interpretative reach, tending to investigate, catalogue and identify relevant data in order to establish analyses and frequency contrasts between ideas, criteria and words that are repetitive or redundant; and, finally, to triangulate the analyses and interpretations obtained from a qualitative triangular exercise (Valles, 1999).

The analysis and interpretation is based on the testimonies of the young people by using the different instruments applied, highlighting reiterations, details, and establishing relationships to account for and present literal perceptions of the young people, under the criteria of collecting a good part of the perceptions expressed and manifested by most of their peers. The analysis and interpretation and the triangulation showed that the young people reiterated their ideas, thoughts and findings.

As we know, working groups in the school environment are usually between 35-40 young people. For the definition of the participants, this research took as criteria the smallest group or course of the eleventh grade, counting with a constant population sample of 21 young people, 11 women and 10 men, between 15 and 18 years old, students of the eleventh grade in the José María Córdoba School.

It is important to point out that the topics proposed for the search in Ático during the micro-ethnographic phase, as well as the development of the visual and audiovisual narratives in the PRVPA, are part of the academic plan- 
ning proposed by the teacher for the eleventh grades. Bearing in mind that this is the last grade, work has being done to identify and recognize the artistic movements of the last three centuries as part of the general history of society and, in particular, history of Colombia. Artistic production and visual-plastic images are understood as part of specific contexts, times and spaces that are not isolated from the social and cultural evolution of different societies.

At the same time, it is necessary to recognize the matrix of much of what is currently known as visual culture or visual ecosystems, where drawing, painting, photography, film, video and multimodal appear as co-participants of languages and iconicities similar to each other, reappropriated, recreated and redefined according to interests and needs in space-time. Art and images have been present in a large part of iconic-visual production, currently known as visual culture, although it has been expanded and broadened not only by the multiple media in which it is treated and reproduced, but above all by the majority access and circulation it has in today's digital culture. To that extent, it is important to recognize and understand images from their creation and production contexts, acquiring other readings, analyses, interpretations and appropriations of digital contexts and the visual culture immersed in them, which tends, at the same time, to a more active and critical participation of young people in reading, access, uses and appropriations.

\section{Results}

After the development of the micro ethnographic work, it was initially found that for the young people it is vital that their daily school life is articulated with their own practices and interests. This is the case with the use of digital tools such as tablets and internet connectivity, showing that having the necessary resources and that their daily lives are satisfactory, generates more motivation and interest in making questions and getting into the information, finding the media and the school itself close by.

It is also evident that they recognize greater access, hence the importance of the Internet in general and the didactic resources they find on YouTube in particular, because in the absence of books, knowledge or access to libraries at any time and any day in an easy and fast way, the Internet and digital culture become a learning tactic for the youngest.

Affirmations or answers from young people, such as: "Having others and more resources to search for information, not only in books but also digitally" (SSI.C.16 years old) or "There is no longer any excuse not to do the work because we have everything around us" (SSI.N.16 years old), are redundant with regard to the different collection instruments and the place that YouTube represents as CTR in its academic activity.

The group of young people with whom we worked, agree on the "ease and speed" of finding information in a more "concrete and specific" way with respect to books. In the same way, the possibility of finding different and varied sources of information, not just one, they point out a preference for audiovisual references to letters in general, finding advantages in simultaneous information between audio and image, as it is more "striking and better", also arguing that it is presented in a "simpler and clearer" way. It is essential that the video is totally audiovisual, so they prefer videos that work in parallel with the visual and auditory, since they also do not feel that they receive or find enough information in videos that only present images without audio or vice versa. In this matter some young people mention:

-I think it's better on video than on a page, one concentrates more on the videos because of the graphics and the illustrations. (SCI. N, 16 years old).

-I like the way you search on YouTube, because it's not like much, I mean it's cool because you learn more things, it has music, they show us images about it too. (SCI. A, 15 years).

-I think the video is much more descriptive than a text. (SCI. C, 16 years old)

Both in semi-structured interviews (SSI), as will be seen later in counter-interviews (CE), youth blogs (YB) and the virtual route (VR), a common and redundant theme is the preference and affinity of young people for manifestations that are beyond the alphanumeric and literate code, for visual and audiovisual forms, as well as other ways of relating, where the narrative is strengthened by both visual and auditive means.

Up to this moment, it is evident from the testimonies of the young people that the results of the investigation at the formal level oscillate, firstly, in the CTRs as instruments and tools that demand to be recognized by the school from the daily life of the young people, secondly, the impact that they have in terms of access to information, which comprises three elements fundamentally recognized by the young people: variability, operability (facility) and opportunity of access. 
Thirdly, it is found that the CTRs present a problem for young people, within the framework of their academic and social work, in relation to the reliability of information; and finally, a transversal element to the three previous ones and a centre of interest for the purposes of this article, which needs to be treated in a particular way, since it configures the ways in which young people relate to the contents, repertoires and cultural dynamics that are sustained by these media. This is about the predominance of visual and audiovisual culture over written culture, which, like visual-Plastic arts education, works and it is develop through images and their narratives.

Authors such as De Bono (1995), Arnheim (1986), Dondis (1976), Taddeo (2019), Rivas (2019), among others, converge on the fact that there is a turning point in terms of moving, or rather, situating alternative modes to this type of language. These other language modes in turn reflect the emergency of other ways of thinking, of accessing information and the construction of knowledge, as well as the modification and renewal of other learning processes, moving from the domain of classical language (alphanumeric and literate) to the domain of "emerging" languages (specifically visual and audiovisual).

-It's another way to learn about artistic movements, let's say in them we can go beyond a theory, because they show us the graphic, also as the characteristics.

-They are new media in which we can learn, new media to handle. (SSi. N, 16 years)

It is possible to indicate that the visualization and explanation of the step by step of the work on a subject is key for the young people, they prefer this to generalized explanations that give concepts and knowledge by fact, comparing it constantly with the reading in books, web pages or the explanations of the teachers at general level. They argue that there are videos in which they are explained and "shown" part by part and if they do not understand it they can return or repeat the video as many times as necessary, which is not possible with classes. They insist that it is "easier and faster than in books", which is more gratifying, because they say that "videos are not as monotonous as books, so they entertain and teach more” (SSI. M, 16 years).

The following testimonies illustrate the mention before:

-I prefer the videos because they show me more like the procedure and more illustration, and the files show me, both show me an objective, but the files show me more handwriting. There are times when one does not concentrate so much on the letter, but captures more with the images, with the illustration. (CE, A, 16 years old)

-The videos explain to us, it's not just reading the pages, an introduction; well, let's say, in the videos there is also an introduction, but they show us images, they show us what they are talking about. (CE. $N$, 16 years)

-I like videos and books more than text pages, for example, when you talk about performance, when you talk about dance, you can see through videos exactly how it is. (CE. K, 16 years old)

Based on what the young people refer to, the videos demand more attention, concentration and other ways of use than the text pages in which they usually cut and copy, without taking much time to review what they say, and in turn they feel that they can interact and manipulate the videos in their own way. In the same way, a need is evident in young people with regard to the meaning of things and situations, since in spite of the fact that these may be visually or audibly attractive to them, if they do not contain meanings and senses for them, they lose interest, requiring - in the case of videos-more than forms and means of entertainment, modes and means of communication and interaction of senses.

-Some reflected, if they had the meaning of what I was looking for, I like the videos the best, they gave us a better explanation, it gives one more to understand. Some I don't like, they don't give as much inspiration to what they were reflecting - very interesting, I liked that the videos show a textual part and of the graphics because one can read the graphics. (EC. A, 15 years).

They find in the use of the videos and their languages more practical ways to access the information, facilitating the processes of accessibility and construction of the learning from other resources and languages, without losing sight of the limitations and aspects to improve of the same ones, demonstrating:

-I didn't like this video, because it doesn't speak clearly about this subject, it only shows works and which part of surrealism it belongs to. (RV. C, 15 years)

-I didn't like this video very much because the way it was explained is not so good, I think, although 
the program is well done. (RV. $N, 17$ years old)

- [...], because it is short you cannot have all the information, there are things that are important and are left out of it. (RV. C, 16 years old).

These uses and appropriations in the case of YouTube, as well as VPA, extend the traditional frameworks of reference in the forms and processes of communication and learning, through the visual and audiovisual. They determine and demonstrate actions or practices, not only communicational but also pedagogical and didactic, adapted and applied by young people for their own benefit.

It is recognized in the young active, critical and sensitive uses and appropriations, which allow the use of the platform from other registers, as a result of the complex interactions between the initial uses, appropriations, practices developed and elaborated later through the VPAE. It should also be pointed out that, within the framework of the usual educational technologies, particularly with regard to visual-Plastic arts and young people, there is a constant comparison between searching in books, text pages and YouTube, despite the fact that, as has been reiterated, not only schools but especially young people are lacking.

It is a matter of having a wide repertoire of possibilities in and from different perspectives, we do not seek to deny the importance of material with alphanumeric content, but rather to highlight its transcendence in the access and construction of knowledge, as well as in the learning processes. However, this implies de-structuring the traditional ways of thinking regarding how knowledge is accessed and constructed through fixed technologies, in order to recognize and structure, not only other technologies, but especially the other forms of language they bring with them and, therefore, those other ways and modes of thinking, from the visual, audiovisual, narrative and their meanings.

Now then, based on the uses and appropriations that young people make of the YouTube platform for the purpose of learning particular knowledge, in the case of visual-Plastic arts education, it is evident that the learning processes through the YouTube platform is more attractive, illustrative, easy and quick to access and use, to the extent that the information is made explicit in two ways: through oral narrative and visual narrative; appealing to the main entrance portals of human information: the eye and the ear, according to the theory of cognitive science.

Authors such as Mayer, Clark (2001, 2010, especially) ${ }^{1}$, McGilly, Keller (1983, 1987, 1989) Dick. W., \& Carey L. (2005) suggest that for the design of learning instructions in general, and in particular with the use of ITC, it should be taken into account that the student learns with words and graphics, that is, by using more than one channel or sensory portal, so they support six principles for the design of educational content based on ITC, privileging the first three ${ }^{2}$ : Multimedia principle, principle of contiguity and modality principle.

Therefore, the learning processes are less linear and closed, they become more variable and dynamic, therefore, they are supposed to be more intertextual, hypertextual, hypermedial and multimodal, thus requiring the inclusion of other alphabets or textualities. As Cassany points out in his book: Online: Reading and Writing on the Net (2012) on current literacy, it is about other ways of reading and learning, where audiovisual, digital and multimodal reading and writing become constitutive of or for learning, determining or characterizing, uses, appropriations and development of communication skills different from the already traditional communication of the alphanumeric literate culture that is part of their learning. In the same way, Germán Rey (2015) states that "the journeys of reading are not far from the visual cartographies of our time" (2015, p. 18), that in other words, from those other forms of audiovisual, hypertextual, and multimedia writing, etc.

\section{Discussion}

These reading journeys and their other visual, audiovisual, hypertextual and multimodal cartographies typical of

\footnotetext{
${ }^{1}$ It is worth mentioning that one of the best known theories is Mayer's “multimedia learning theory", based on the idea that there are three types of storage in the memory and that each person has separate channels to process verbal and visual information, and that learning takes place when both types of information are processed at the same time. Hence the importance of the theory of cognitive science taken up and proposed by Mayer and Clark to understand and comprehend how people learn, as well as Keller's first step: to know and identify the elements of human motivation, for the case of analyzing the characteristics of student-youth for motivational design.

${ }^{2}$ Multimedia principle: use of words and graphics in the design of content is more attractive and effective according to the theory of cognitive science. Contiguity principle: words and graphics should not be the same meaning, but should have analogies, as well as visual and spatial proximity. Modality principle that involves the combination of perception and memory, through the use of different modes of expression and/or language, that is, using more than one channel or medium to learn. The other three principles are: Principle of Redundancy, Principle of Coherence, Principle of Personalization.
} 
current CTR and digital practices of young people, as well as of VPA, imply other views, readings and configurations with respect to language. It calls for an approach that goes beyond its "precise and trivial sense of natural language" (Todorov and Ducrot, n.d., p. 5), or as a system of signs, which has been traditionally defined as a set of phonemes that have a significant meaning or intention, that are constituted as fundamental elements of communication. It is necessary to assume the language from the configurations of the visual and audiovisual narratives, typical of the visual and audiovisual culture of the CTR, also talking about the visual, audiovisual and narrative language where the images play a preponderant role, whether they are fixed or in movement.

The possibility is then opened up around language applied and expanded to other systems of signs and therefore of communication, such as visual, audiovisual, narrative and multimodal language, among others. As it is developed and worked from the CTR and through the VPAE from wider points of view, they could be understood as significant articulations that are not necessarily and directly regulated by the word or the letter, but that counts for the structure of language, in particular ways and under specific manifestations.

To that extend, as was pointed out, this research encounters a reconfiguration of the forms of language, where the visual and audiovisual modify the relations of the educational sphere, knowledge and actors. According to Barbero and Rey (1999), changes are taking place in the ways knowledge circulates, where reading and learning no longer exclusively concern to books, but the plurality, diversity and heterogeneity of texts, stories, writings — oral, visual, sound, audiovisual, digital. Likewise, transformations are produced in the dissemination and circulation of knowledge, with the emergence of other cultures, other ways of seeing, reading, learning, and knowing, which involves different processes of reading and writing given the complex articulations and convergences of different languages, thus also reconfiguring ways of thinking.

Authors such as Renés-Arellano, Pérez-Lisboa, Hinojosa-Becerra, Caldeiro-Pedreira (2019), state that, “The digital gap implies a cognitive gap related to the different ways of processing information and audiovisual content and to their understanding (p. 126). Therefore, the new languages generate other systems of adaptation to cognitive conditions, which urge, in the words of Serres (2013), to leave the spatial format implied by the book and the page. Likewise, according to Pardo (2012), language requires the expansion of its conceptions and viewpoints that link interdisciplinary or transdisciplinary developments (Ranciere, 2012) in order to cover the multiplicity of signs -multisignificant - that potentialize discourses and narratives, and therefore modify the cognitive and thought schemes established historically and traditionally".

\section{Conclusions}

In this way, from the use and appropriation that young people made of YouTube, it can be established that these visual-languages and audio-visual — without being new, they are found to have more access and coverage of the population in general and in particular of young people, thanks to the development and boom of the CTR with the web 2.0. The young people of this time have grown up, not only in the middle of the television and video world, but especially in the web and its forms of cultural convergence, incorporating pedagogical and cultural practices to daily life through digital uses and appropriations, through which languages are enriched and other pedagogical models are demanded, especially visual and audiovisual ones, as another of the mechanisms of language that is more appealing, illustrative and easy to understand for young people.

This does not necessarily imply that learning or cognitive processes, per se, are produced, but, the visual, audiovisual and narrative, implies a form of language that is more binding as an initial level of information, communication and learning. It recognizes in visual, audiovisual and multimodal media, logics and different modes of communication, in which oral and visual forms, technologies of orality and visuality converge. It is no longer only the school that faces the problem of knowledge, since it is on the web under information or elaborations that are more "rigorous" than others, its circulation or modes of access, but also, in a fundamental way, on the work of education. It is a matter of the ways in which knowledge is questioned in the configuration of these new relations of meaning and the ways in which links are constructed through these platforms.

So, in the apparent passage from literate culture to visual and audiovisual culture, in which images and their technological extensions have a place, in order to have wide repertoires and possibilities from different perspectives, other forms of language and therefore of thought are structured and unstructured. This is a question that visual-Plastic-artistic education renews and revives, insofar as the image transgresses what the formal structure of language constitutes, since not only the formal processes of meaning are inscribed in the image, but also the very experience of those who produce and those who position themselves as spectators before it. The image, added to the 
auditive, poses a practice, an invocative experience that transcends the perceptive processes and concerns the very experience of production and relationship with the knowledge that surrounds the school.

The question of education, of young people and of the CTRs in relation to the VPAE, demands that studies on image and language go into the understanding of the effects and transformations that are generated in a culture that is increasingly exploring the forms of its constitution, of organization and sustainability based on aesthetic transformation and the production of meaning around the image. This implies for education in general and its entities in particular (schools, colleges, teachers, etc.), recognizing and understanding that young people learn in very diverse ways through different languages. This means that the more diverse the ways, forms, or languages of relating to knowledge, the more connections can be established between how they learn and what they understand based on the stimulation of the senses, allowing young people not only to learn according to own learning styles, but also to develop repertoires of different thinking strategies, beyond the culture of letters and alphanumeric letters, or better, beyond the homogenization of codes.

\section{Acknowledgments}

This article is the result of the research entitled "Visual and plastic artistic education in digital contexts: uses and appropriations of the young people of the YouTube platform", which is being developed since 2012 and finished in 2019, therefore some extracts from it were used here. Doctoral thesis, Interinstitutional Doctorate in Education (IDE), Universidad Distrital Francisco José de Caldas, Universidad Pedagógica Nacional and Universidad del Valle.

\section{References}

Aguaded, I. Cabero, J. (coord.) (2013). Technologies and means for the education in society. Madrid, Spain: Alilliance.

Arnheim, R. (1986). Visual thinking. Buenos aires, Argentina: University.

Barbero, J. M. (1996). Inheriting the future. Thinking about education from communication Nomads (Col), núm. 5, Universidad Central Bogotá, Colombia.

Barbero, J. M., Rey, G. (1999). The exercises of seeing. Barcelona, España: Gedisa.

Barbero, J. M. (2003). From media to mediations. Comunication, culture and hegemony. Bogotá, Colombia: Convenio Andrés Bello.

Barbero, J. M. (2013). The education from comunication. Bogotá, Colombia: Grupo Editorial Norma.

Caldeiro-Pedreira, M. C., Aguaded, I., \& Peréz-Rodríguez, A. (2019). Educomunication and good practices in new technological: Analysis of the Galician case (Spain). Hamutay, 6(1), 96-111. https://doi.org/10.21503/hamu.v6i1.1577.

Cassany, D. (2012). Online: read and write online. Barcelona, España: Anagrama.

Corbetta, C., Dussel, I. (2018). 2 Visual repertories in arts education. Art history, global visual culture and curriculum in the visual collections of Argentine teachers São Cristóvão, Sergipe, Brasil, v. 11, n. 26, 15-38.

Chapato, M., Dimatteo, M. (2014). Scope of Artistic Education at the begining of a new millennium. In Art Education. Emerging horizons, scenarios and practices. Buenos Aíres. Argentina: Biblos.

De Bono, E. (1995). Parallel Thinking. Barcelona, Spain: Paidós.

Dondis, A. (1976). The syntax of the image. Introduction to the visual alphabet. Barcelona, Spain: Gustavo Gili.

Ducrot, O. Todorov, T. (S.F.) Specialized encyclopedic dictionary of language sciences.

Eisner, E. (1995). Educate the artistic vision. Barcelona, Spain: Paidós.

Freedman, K. (2006). Teach visual culture: curriculum, aesthetics and the social life of art. Barcelona, Spain: Octaedro.

Mirzoeff, N. (2006). The visual culture reader: by Routledge.

Pardo, A. (2012). Discourse on the web: poverty on Youtube. Bogotá, Colombia: Grafiweb.

Pérez-Rodríguez, M. A, Delgado-Ponce, A., García-Ruiz, R., \& Caldeiro-Pedreira, M. C. (2015). Children and Young people before the networks and screens. Barcelona: Gedisa.

Renés-Arellano, P., Pérez-Lisboa, R., Mónica Hinojosa-Becerra \& M. (2019). Media education in ibero-American pedagogy of XXI century: Its meanings, values and critical expression.In media and digital competence from acces to empowerment. Madrid. Spain: Group communicate editions.

Rey, G. (2015). The journeys of the readers. In Memories 12 National Reading Congress. Digital Reading.Bogotá. Co- 
lombia: Nomos.

Rivas, A. (2019). What is there to learn today? From the school of the answers to the school of the questions. Bogotá, Colombia: Fundación Santillana.

Rueda, R., Fonseca, A., \&Ramírez (eds.) (2013). Cyber-citizenships, political culture and social creativity. Bogotá, Colombia: DIE-National Pedagogical University.

Serres, M. (2013). Thumbelina. Buenos Aíres, Argentina: Fondo de Cultura Económica.

Taddeo, G. (2019). The use of digital to develop informal learning strategies: Studies and tolos. In Media and digital competence: From the Access to empowerment. Madrid. Spain: Group communicate editions.

Tirocchi, S. (2019). Teachers and new responsabilities of culture mediation: scenarios and stimuli in an Italian contex. In media and digital competence: From Access to empowerment. Madrid. España: Grupo comunicar ediciones. 